\title{
Mass Panic during COVID-19 Outbreak-A perspective from Bangladesh as a High-Risk Country
}

\author{
Mohammad Sorowar Hossain ${ }^{1,2, *}$, Shameema Ferdous ${ }^{1}$, and \\ Mahbubul H Siddiqee ${ }^{3}$ \\ ${ }^{1}$ Biomedical Research Foundation, Dhaka, Bangladesh \\ ${ }^{2}$ Independent University, Bangladesh (IUB), Dhaka, Bangladesh \\ ${ }^{3}$ Molecular and Environmental Microbiology Laboratory, BRAC University, Dhaka, Bangladesh \\ "Corrresponding author: sorowar.hossain@brfbd.org
}

Received: March 24, 2020; revised: April 30, 2020; accepted: May 1, 2020.

\begin{abstract}
COVID-19 outbreak has generated mass panic worldwide because of misinformation, rumors, exaggeration of impending scenarios, and fake news circulating in social media and traditional media portals. As a consequence, it has triggered panic-buying, racism, and mistrust in the community. Mass panic could also disrupt the supply chains of all necessary items and lead to unnecessary hospital visits. Trust is the cornerstone of public health countermeasures. In settings with mistrust on public authorities, the engagement of eminent researchers, trustworthy public figures, and community leaders (imam of mosques) could be effective in mitigating mass panic.
\end{abstract}

Keywords: COVID-19, Bangladesh, Dhaka, Corona Virus

The world has been confronting COVID-19 pandemic, caused by severe acute respiratory syndrome coronavirus 2 (SARS-CoV-2). Originating in Wuhan, China, it already spread to 196 countries (26 March 2020). Due to its fatality and high transmissibility, COVID-19 has been highlighted in print and online media portals globally. While such media attention helped to communicate important updates with mass people, it has also generated detrimental effects. It has triggered panic-buying, racism (including physical assaults), and mistrust even in places where cases are not officially confirmed, or few cases are reported (Shimizu, 2020). For instance, even before reporting the first case (8 March 2020) from Bangladesh, 
mass panic is highly visible: incidence of family relationship breakdown, patients and staff fleeing from a hospital after the admission of an expatriate man with flu-like symptoms (Kamal, 2020; Daily Bangladesh, 2020). In India, protests from patients and attendants erupted over the opening of a COVID-19 isolation ward in the hospital (Gulf News, 2020).

Mass panic is usually generated due to misinformation, rumors, exaggeration of impending scenarios, and fake news circulating in social media and traditional media outlets. Such panic could disrupt the supply chains of all necessary items and lead to unnecessary hospital visits. Hence, understanding the root causes of public health panic is critical to take preventive measures.

While developed countries with better-equipped healthcare systems are even struggling enormously to confront COVID-19, the situation is expected to be much worse for many resource-limited countries where the existing weak healthcare system is already stretched thin. Diseases like COVID-19 would quickly overwhelm them.

COVID-19 is a ticking time-bomb for Dhaka- the capital city of Bangladesh. This is the most crowded megacity in the world, with nearly 20 million people (47000/sq km compared to $1300 /$ sq in Wuhan) (New Geography, 2020). Unlike well-developed cities in China and Italy, it is nearly impossible to lock down Dhaka to contain COVID-19 since this is the hub of all economic, educational, and administrative activities of Bangladesh. It is important to emphasize here that Dhaka was devastated by a recent dengue outbreak (2019) when panic disrupted the healthcare system (The Independent, 2020). With such a backdrop, highly contagious COVID-19 could make the situation chaotic and unmanageable in Bangladesh and other similar settings.

Trust is the cornerstone of public health countermeasures. For building a high level of trust during a crisis like a pandemic, some critical issues need to be prioritized for effective risk communications and interventions: acknowledging the uncertainty of the real situation (forecast and warning), being transparent and not cover up negative information (such as fatality rate) (WHO, 2017), speedy disseminating of easily understandable scientific information through multiple channels. In the context of developing countries like Bangladesh, where people generally have mistrust on public authorities, mass panic could effectively be mitigated by engaging eminent researchers, trustworthy public figures and community leaders, particularly religious scholars (imam of mosques).

\section{Acknowledgments}

We would like to thank Professor Miles Carroll, National Infection Service, Public Health England, UK, for reviewing the manuscript.

\section{Declarations}

Funding: There was no funding received for this commentary. Conflict of interest: The authors declare no conflict of interest. Ethical approval: Not applicable.

BRF Www.jBiomedAnalytics.org 


\section{References}

Daily Bangladesh (2020). "Singapore expatriate wife leaves home over coronavirus panic." Accessed March 8, 2020, URL https://www.daily-bangladesh.com/english/ Singapore-expatriate-wife-leaves-home-over-coronavirus-panic/37217.

Gulf News (2020). "Coronavirus: Anxiety grips Hyderabad despite government reassurances." Accessed March 8, 2020, URL https://gulfnews.com/world/asia/india/ coronavirus-anxiety-grips-hyderabad-despite-government-reassurances-1.70122105.

Kamal RS (2020). "Fear, hatred and stigmatization grip Bangladesh amid Covid19 outbreak." Accessed March 8, 2020, URL https://tbsnews.net/thoughts/ fear-hatred-and-stigmatization-grip-bangladesh-amid-covid-19-outbreak-61129.

New Geography (2020). "The 37 Megacities and largest cities: Demographia world urban areas:2017." Accessed March 8, 2020, URL http://www.newgeography.com/content/ 005593-the-largest-cities-demographia-world-urban-areas- 2017.

Shimizu K (2020). “2019-nCoV, fake news, and racism.” The Lancet, 395(10225), 685-686. doi:https://doi.org/10.1016/S0140-6736(20)30357-3.

The Independent (2020). "Dengue panic disrupts hospital operations." Accessed March 8, 2020, URL http://www.theindependentbd.com/post/210208.

WHO (2017). Communicating risk in public health emergencies: a WHO guideline for emergency risk communication (ERC) policy and practice. World Health Organization. 